\title{
ASSOCIAÇÃO ENTRE CARACTERÍSTICAS AGRONÔMICAS \\ DA BATATA NOS PLANTIOS DE PRIMAVERA E OUTONO NO RIO GRANDE DO SUL ${ }^{1}$
}

\author{
Association between potato agronomic characteristics in spring \\ and autumn growing seasons in Rio Grande do Sul
}

\author{
Mario Alejandro Andreu²
}

\begin{abstract}
RESUMO
Conduziu-se este trabalho com o objetivo de identificar aquelas características da batata (Solanum tuberosum L.) que possuam maior estabilidade adaptativa e importância agronômica para as condições climáticas contrastantes de outono e primavera do Rio Grande do Sul. Foram avaliadas a maturidade, número médio de tubérculos, produtividade por planta, textura, formato, profundidade dos "olhos" e aparência geral dos tubérculos. Foram observadas reduções nas médias tanto para qualidade como para a produtividade dos tubérculos na safra de outono em comparação com a safra de primavera, devido às maiores variações na temperatura, radiação e fotoperíodo. Os coeficientes de variação foram maiores no cultivo de outono, sendo relativamente altos para produção por planta, número médio de tubérculos, textura e aparência geral. Foram observados coeficientes de correlação moderadamente altos e significativos $(\mathrm{r}<0,80)$ para textura, formato e profundidade dos olhos, e baixos $(\mathrm{r}<0,40)$ para maturidade, número médio de tubérculos, produção por planta e aparência geral. Os resultados deste estudo mostraram que para a população e características estudadas, a produtividade por planta e número médio de tubérculos não são parâmetros constantes quando consideradas safras climatológicamente contrastantes. Características como textura, formato e profundidade dos olhos podem sofrer altas intensidades de seleção por possuírem alta estabilidade. A seleção baseada em aparência geral dos tubérculos deve ser mais intensa na primavera, quando os parâmetros de qualidade e produtividade estão maximizados.
\end{abstract}

Termos para indexação: Solanum tuberosum, batata, seleção, clima.

\begin{abstract}
The objective of this work was to identify potato characteristics that have higher adaptation stability for important agronomic characteristics for the contrasting autumn and spring climatic conditions of Rio Grande do Sul, Brazil. The tuber characteristics evaluated were maturity, average number of tuber plant yield, texture, tuber shape, depth of eyes and general appearance. Reduced tuber quality and yield were observed in the autumn crop compared to the spring, due to variations in temperature, radiation and photoperiod. Coefficient of variation were higher in the autumn, in particular for plant yield, average number of tubers, texture and general appearance. Correlation coefficients were moderately high and significant $(r<0,80)$ for texture, tuber shape and depth of eyes, and low $(r<0,40)$ for maturity, number of tubers, plant yield and general appearance. The results of this study showed that the characteristics and population studied, the plant productivity and number of tubers are not constant parameters comparing crops in contrasting climates. Characteristics such as texture, tuber shape and depth of eyes can be selected with high intensities, based on their high stability. Selection based on tuber general appearance may be more intense in the spring, when the quality and productivity parameters are maximized.
\end{abstract}

Index terms: Solanum tuberosum, potato, selection, environment.

(Recebido para publicação em 11 de setembro de 2003 e aprovado em 18 de janeiro de 2005)

\section{INTRODUÇÃO}

As principais safras na cultura da batata (Solanum tuberosum L.) na região sul do Brasil, são a safra "das águas" ou de primavera, plantada durante os meses de agosto até dezembro e colhida desde novembro em diante, e o plantio de fevereiro até junho constitui a safra "de outono" (FUROMOTO, 1997). Estas duas épocas do ano são climatológicamente contrastantes e conseqüentemente, afetam diferencialmente as características agronômicas das diversas cultivares plantadas nesta região. O plantio de primavera caracteriza-se por fotoperíodos, temperaturas e radiação crescentes e, pelo contrário, o outono caracterizase por fotoperíodos, temperaturas e radiação decrescentes (PEREIRA, 1999). Esses fatores influenciam diretamente a fisiologia da parte aérea das plantas de batata e portanto, afetam o metabolismo dos tubérculos, podendo limitar o potencial produtivo e de qualidade dos mesmos. $\mathrm{O}$ bom desempenho de determinados genótipos no lugar ou época onde foram selecionados ou lançados, não asseguram o sucesso em regiões com condições ambientais diferentes, visto que o comportamento varia em função das condições edafoclimáticas, doenças, épocas de plantio e práticas culturais.

'Parte da dissertação de graduação para obter o título de Licenciado en Genética apresentada pelo autor à Universidad Nacional de Misiones/ Posadas - Misiones - Argentina.

${ }^{2}$ Mestrando em Genética e Melh. de Plantas / UFLA / DBI-GEN, Cx. P. 3037 - 37.200-000 - Lavras, MG - marioandreu@ig.com.br 
A safra de outono constitui uma boa alternativa para os produtores da região sul do Brasil principalmente pelos retornos econômicos, mas neste período o cultivo é limitado pela presença freqüente de doenças fúngicas como a requeima e a pinta preta, favorecidas pelas condições climáticas de alta umidade associada à baixas e altas temperaturas, respectivamente. Portanto, as condições de cultivo de primavera são mais favoráveis para o desenvolvimento da maioria das cultivares, sendo estas mais produtivas e de melhor qualidade (COSTA \& LOPES, 1981; PEREIRA, 1999). Por essa razão, se faz necessário que os programas de melhoramento apontem suas pesquisas à identificação e avaliação daquelas características agronômicas intrínsecas da batata que apresentam maior adaptação e estabilidade nas duas épocas de cultivo de Rio Grande do Sul, para desenvolver e adotar as cultivares ou clones de melhor desempenho de acordo com a eficiência da seleção. Embora a identificação destes genótipos superiores, se faça através de populações melhoradas derivadas de vários ciclos de seleção nas diferentes épocas de cultivo, o principal problema é que, a maioria das características de interesse agronômico e industrial são herdadas quantitativamente e portanto, influenciadas pelo ambiente, o que dificulta muitas das determinações de caráter subjetivo realizadas pelos melhoristas (BARBOSA \& PINTO, 1988).

Deve-se considerar ainda que a melhor estratégia de seleção dos melhores materiais depende também do nível de expressão dos caracteres fenotípicos, os quais têm diferentes níveis de herdabilidade. Um bom indicador da herdabilidade é a correlação entre caracteres entre as diferentes gerações (MARIS, 1988). Contudo, é importante conhecer a magnitude das variações e correlações das características consideradas entre os períodos de cultivo a fim de estabelecer uma efetiva estratégia de seleção nos períodos de outono e primavera.

Objetivou-se com este trabalho avaliar e identificar características que possuam maior estabilidade adaptativa para as características de importância agronômica, nas condições contrastantes de cultivo de outono e primavera do Rio Grande do Sul.

\section{MATERIAL E MÉTODOS}

\section{Experimento e Procedimento Experimental}

Os trabalhos foram iniciados com uma amostra de dez populações híbridas de batata. Usaram-se as seguintes combinações de genitores: Atlantic x Macaca; Cristal x Atlantic; C-1485-6-87 x Atlantic; C-1226-35-80 x Asterix; Rioja x Macaca; Baronesa x Monalisa; Monte Bonito x Asterix; Lady Rosetta x Macaca; Cristal x Monalisa; Agria x Baronesa. Os experimentos foram conduzidos em Pelotas ( $\left.32^{\circ} 41^{\prime} \mathrm{S}\right)$, RS. O solo utilizado foi classificado como Podzólico Vermelho - Amarelo Eutrófico e adubado com $2000 \mathrm{Kg}$. ha ${ }^{-1}$ de NPK (5-20-10) na primeira geração clonal e (10-20-10) na segunda geração clonal. A abertura dos sulcos, o plantio e a colheita, foram manuais, e os tratos culturais e fitossanitários foram realizadas segundo os manuais técnicos da EMBRAPA Clima Temperado (EMBRAPA, 1993). As plantas foram espaçadas a $30 \mathrm{~cm}$ no sulco e uma distancia de $80 \mathrm{~cm}$ entre os sulcos.

Cultivo de primavera: 800 clones de batata foram avaliados. Os tubérculos provinham de sementes botânicas de batata. O delineamento experimental foi de blocos ao acaso, com 4 repetições e 10 plantas por parcela.

Cultivo de outono: avaliaram-se 400 clones provenientes do cultivo de primavera, distribuídos num delineamento experimental de blocos ao acaso com 4 repetições e a unidade experimental de 11 linhas de 5 plantas.

As características avaliadas nos dois experimentos foram a maturidade das plantas segundo o grau de senescência antes da colheita $(1=$ precoce; 5 = tardia); número e peso médio de tubérculos, índice de formato dos tubérculos derivado da relação comprimento / largura: redonda (1) - oval (2) - oval alongado (3) - alongado (4); textura, lisa (1) - áspera (2); profundidade dos olhos, salientes (1) - superficiais (2) semiprofundas (3) - profundas (4); aparência geral, (1 = ruim $-4=$ muito bom). Foram calculadas médias, amplitudes, coeficientes de variação e de correlação entre as diferentes safras.

\section{RESULTADOS E DISCUSSÃO}

Houve influência das duas épocas de cultivo, particularmente para maturidade da planta, produção por planta, textura e aparência geral dos tubérculos (Tabela 1).

Segundo Lemaga \& Caesar (1990), estes resultados seriam esperados fundamentalmente porque as condições climáticas contrastantes para cada plantio, sobretudo no que se refere à temperatura, fotoperíodo e radiação, favorecem as diferenças entre clones e entre cultivares em condições subtropicais.

Ciênc. agrotec., Lavras, v. 29, n. 5, p. 925-929, set./out., 2005 
TABELA 1 - Médias, amplitudes, coeficientes de variação e correlação dos cultivos de primavera de 2000 e outono de 2001 para algumas características agronômicas dos clones de batata.

\begin{tabular}{lcccccccc}
\hline \multicolumn{1}{c}{ Características } & \multicolumn{2}{c}{ Médias } & & Amplitudes & & C. V. & $(\mathbf{r})$ \\
\hline & Primavera & Outono & Primavera & Outono & Primavera & Outono \\
Maturidade & $2,65 \mathrm{a}^{1}$ & $3,05 \mathrm{~b}^{1}$ & $1-5$ & $1-5$ & 23,52 & 25,78 & $0,43 *$ \\
Número médio de tubérculos & $7,10 \mathrm{a}$ & $6,38 \mathrm{a}$ & $4,44-14,0$ & $2-15$ & $22,07 \%$ & $28,65 \%$ & 0,14 \\
Produção por planta $(\mathrm{g})$ & $442,33 \mathrm{a}$ & $271,07 \mathrm{~b}$ & $227-958$ & $53-644$ & $32,21 \%$ & $31,62 \%$ & $0,38 *$ \\
Textura & $2 \mathrm{a}$ & $1 \mathrm{~b}$ & $1-2$ & $1-2$ & $19,40 \%$ & $25,37 \%$ & $0,71 * *$ \\
Formato & $3 \mathrm{a}$ & $3 \mathrm{a}$ & $1-4$ & $1-4$ & $18,67 \%$ & $16,08 \%$ & $0,75 * *$ \\
Profundidade dos olhos & $3 \mathrm{a}$ & $3 \mathrm{a}$ & $1-4$ & $1-4$ & $12,93 \%$ & $14,44 \%$ & $0,73 * *$ \\
Aparência Geral & $3 \mathrm{a}$ & $2 \mathrm{~b}$ & $2-4$ & $1-4$ & $12,91 \%$ & $32,78 \%$ & $-0,07$ \\
\hline
\end{tabular}

** $\mathrm{e} *$ significativo a $(\mathrm{P}<0,01)$ e $(\mathrm{P}<0,05)$ pelo teste $\mathrm{t}$ respectivamente.

${ }^{1}$ As médias seguidas pela mesma letra não diferem entre si pelo teste de $\operatorname{Scott}-\operatorname{Knott}(\mathrm{P}<0,05)$.

A safra de primavera, destacou-se pela presença de tubérculos com maiores valores para produção por planta e número médio de tubérculos (Tabela 1). Estes resultados estiveram dentro do esperado, de acordo com as pesquisas realizadas por Costa \& Lopes (1981) sobre o análise da tuberização de cinco cultivares de batata nos dois períodos de plantio da região sul de Rio Grande do Sul. Os valores observados para as características anteriormente mencionadas, se devem principalmente ao fotoperíodo mais curto na safra de outono (PEREIRA \& CAMPOS, 1999) que, combinado às baixas temperaturas e a alta umidade relativa do ar, dificultaram a expansão da área foliar e conseqüentemente da taxa fotossintética, resultando num menor crecimento dos tubérculos. Estas condições também propiciaram a presença de doenças fúngicas durante o outono, no momento crítico da tuberização, o que contribui também para uma diminuição na capacidade produtiva.

A textura e a aparência geral dos tubérculos também apresentaram diferencias entre as duas safras. A textura é uma característica importante para o consumidor que adquire o produto in natura, embora seja de menor importância para a indústria. Nota-se que durante o outono, os tubérculos foram predominantemente de pele lisa, mas este fato não foi relevante para elevar a média da aparência geral (Tabela 1). Uma explicação possível para a variação de uma safra para outra da textura da pele é que, apesar de ter alta herdabilidade, esta característica é altamente afetada pelas variações ambientais como a umidade, tipo de solo e doenças (FUROMOTO, 1997). Portanto, os tubérculos indesejados quanto à pele, foram eliminados, com o que se consegue com relativa eficiência obter na geração seguinte, clones com tubérculos de pele mais lisa. A seleção baseada na aparência geral dos tubérculos que formaram parte dos clones que constituíram o plantio de outono, não foi consistente de um período ao outro, pelo fato dos clones terem sido favorecidos pelas melhores condições ambientais da safra de primavera. Embora a aparência geral seja um caráter subjetivo e dependente da experiência do melhorista, no outono, a média para aparência diminuiu conforme as condições climáticas tornaram-se adversas para o normal desenvolvimento do cultivo da batata.

O formato dos tubérculos foi predominantemente oval-alongado e os "olhos" tiveram uma profundidade semi-superficial (Tabela 1). Estas características apresentaram consistência tanto nas condições de cultivo de primavera como de outono, porque poderiam ser características fortemente ligadas ao genótipo, o que permite uma maior eficiência com a seleção em qualquer época de cultivo ou fase de melhoramento. Segundo Jong \& Burns (1993), cada cultivar possui um formato e profundidade de "olhos" particulares em seus tubérculos comerciais, sendo estas características facilmente controladas pelo genótipo e pouco influenciadas pelo ambiente, embora possam ser alteradas pelo manejo da lavoura, a densidade de plantio e o ciclo da planta. 
As amplitudes entre as duas safras deram uma idéia aproximada da variabilidade existente para avaliar e selecionar dentro das famílias para as melhores características nas duas épocas consideradas. $\mathrm{O}$ valor de amplitude que sofreu maior variação foi o de produção por planta, em que se observou uma diminuição no tamanho dos tubérculos produzidos individualmente pelas plantas, afetados pelas condições do outono (Tabela 1).

Os coeficientes de variação são indicativos da variação fenotípica e da ampla variabilidade existente para todas as características, sendo maiores para maturidade, produção por planta e número médio de tubérculos, tanto na primavera como no outono, devido à ampla divergência entre as plantas quando consideradas diferentes populações híbridas nas primeiras gerações clonais. A aparência geral dos tubérculos teve também um coeficiente de variação alto no outono, incrementado pela influência das variações climáticas predominantes, o que indicou que os genótipos responderam diferencialmente as pressões ambientais, sendo possível neste período, encontrar genótipos de boa aparência (Tabela 1). Porém, esta característica apresentou um baixo coeficiente na primavera já que os genótipos geralmente foram mais uniformes e de melhor qualidade. Também foram observados coeficientes de variação relativamente baixos para formato e profundidade dos olhos nos dois períodos (Tabela 1), sendo caracteres com pouca variação, provavelmente devido à baixa interação genótipos por ambientes. A textura, apresentou o maior coeficiente de variação durante a safra de outono, devido a ser maiormente afetada pelas condições de umidade e temperatura do solo.

As magnitudes dos coeficientes de correlação entre os períodos de cultivo foram significativas, exceto para a aparência geral e número médio de tubérculos por planta (Tabela 1). A produção por planta e a aparência geral tiveram baixas magnitudes de associação, ao contrário da correlação entre períodos para maturidade e número médio de tubérculos que foi moderada e significativa $(\mathrm{P}<0,05)$. Isto indicou que, independentemente das condições de cultivo as características mencionadas anteriormente exigem uma baixa intensidade de seleção para não prejudicar as populações posteriores formadas a partir delas. Além disso, estas magnitudes indicam que as seleções no cultivo de primavera não seriam necessariamente eficientes no cultivo de outono.

Coeficientes de correlação altos e significativos ( $P$ $<0,01)$ foram observados para textura, formato e profundidade dos “olhos” (Tabela 1). Estes resultados são coincidentes com os encontrados por Gopal et al. (1992) para cultivares de batata comerciais, indicando que, apesar das diferenças ambientais e a diversidade genética avaliada, esses caracteres podem sofrer intensidades de seleção maiores em qualquer geração clonal. Procedendo dessa forma, a seleção individual dos clones poderia ser eficiente na escolha de genótipos que combinem o formato, a textura e a profundidade dos "olhos" desejados, que somados à características de produtividade, ajudariam na melhoria nos índices de aparência geral e portanto, na seleção precoce de genótipos promissores.

\section{CONCLUSÕES}

Para as populações e as condições em que foram efetuados estes estudos, pode se concluir que:

a) A seleção para quantidade e qualidade dos tubérculos baseada em características como produção por planta, número médio de tubérculos e aparência geral, não é eficiente quando são considerados períodos contrastantes de cultivo.

b) Os caracteres textura da pele, formato e profundidade dos "olhos" dos tubérculos, foram altamente correlacionas entre os períodos de cultivo, e portanto, são características com pouca interação entre genótipos e o ambiente de cultivo.

c) Recomenda-se praticar uma seleção mais intensa na safra de primavera devido às condições climáticas serem mais favoráveis, maximizando as características de qualidade e produtividade.

\section{AGRADECIMENTOS}

À equipe de apoio do programa de melhoramento da batata da EMBRAPA Clima Temperado, que com sua ajuda fizeram possível este trabalho.

\section{REFERÊNCIAS BIBLIOGRÁFICAS}

BARBOSA, M. H. P.; PINTO, C. A. B. P. Eficiência de índices de seleção na identificação de clones superiores de batata. Pesquisa Agropecuária Brasileira, Brasília, v. 33, n. 2, p. 49-156, 1988.

COSTA, D. M. da; LOPES, N. F. Período e velocidade de tuberização em cinco cultivares de Batata (Solanum tubeosum L.). Revista Ceres, Viçosa, v. 28, p. 530-545, 1981.

EMPRESA BRASILEIRA DE PESQUISA AGROPECUÁRIA. Cultura da batata. Pelotas, 1993. 5 p. (Sistema simplificado de produção, 1). 
FUROMOTO, O. Épocas de plantio. In: LOPES, C. A.; BUSO, J. A. Cultivo da batata (Solanum tuberosum L.): instruções técnicas Embrapa hortaliças. Brasília, DF: EMBRAPA, 1997. p. 9-10.

GOPAL, J.; GAUR, P. C.; RANA, M. S. Early generation selection for agronomic characters in a potato breeding programme. Theoretical and Applied Genetics, New York, v. 84, p. 709-713, 1992.

JONG, H. de; BURNS, V. J. Inheritance of tuber shape in cultivated diploid potatoes. American Potato Journal, Orono, v. 70, n. 3, p. 267-283, 1993.

LEMAGA, B.; CAESAR, K. Relationships between numbers of main stems and yield components of potato (Solanum tuberosum L. cv. Erntestolz) as influenced by different day lengths. Potato Research, Wageningen, v. 33, p. 257-267, 1990.

MARIS, B. Correlations within and between characters between and within generation as a measure for early generation selection in potato breeding. Euphytica, Wageningen, v. 37, p. 205-224, 1988.

PEREIRA, A. da S. Correlações entre cultivo de primavera e de outono para algumas características agronômicas em batata. Agropecuária Clima Temperado, Pelotas, v. 2, n. 2 , p. 207-212, 1999.

PEREIRA, A. da S.; CAMPOS, A. Teor de açúcar em genótipos de batata (Solanum tuberosum L.). Ciência Rural, Santa Maria, v. 29, n. 1, p. 13-16, 1999. 